\title{
How is the Statistical Literacy of Upper Secondary Students Based on Gender Differences?
}

\author{
Erlyanna Nur Risqi ${ }^{1}$, Rooselyna Ekawati ${ }^{2}$ \\ ${ }^{1}$ Universitas Negeri Surabaya, erlyanna.17030174026@mhs.unesa.ac.id \\ ${ }^{2}$ Universitas Negeri Surabaya, rooselynaekawati@unesa.ac.id
}

\begin{abstract}
The study aimed to describe the statistical literacy of upper secondary student based on gender differences. There are a gap between female sex is not necessarily feminine and conversely male students are not necessarily masculine, there is a possibility that the person is of type androgyny or indistinguishable. The study was conducted in four students with different gender type that is masculine type, feminine type, androgynous type, and indistinguished type. Data was collected using the Statistical Literacy Test, developed based on the statistical framework about statistical literacy ability with indicator of understanding data, interpreting data, and communicating data. The result with quantitave and qualitative research revealed significant differences statistical literacy based on gender differences. In this study shows that the feminine type has the highest statistical literacy skill between other gender types in understanding data, interpreting data, and communicating data. In understanding data, the feminine type can read data and supported with arguments that are easily understood. In interpreting data, feminine type are able to make predictions of future possibilities, can determine the value of increase and decrease in data, able to think critically about the data presented and able to make conclusions based on the data. But, in communicating data feminine type make mistakes in changing the shape of data from graphs to table forms. Then, statistical literacy ability followed by androgynous type. Then, the lowest statistical ability in the masculine type and the cannot be distinguished type.
\end{abstract}

Keyword: Statistical Literacy, Upper Secondary Students, Gender.

\section{Introduction}

Statistical literacy, which is the point at which statistics and probability intersect in people's daily life [1], is an important skill that individuals need to acquire in the current information age [2]. It is prerequisite for all people engaged in the critical questioning of a large body of information [3]. Statistical literacy's indicator are reading data, interpreting data, and summarizing the data [4]. In the current century, statistical literacy is essential for children in their decision-making process since different data representations or report regarding these representations may easily mislead [5]. Furthermore, the Guidelines and Assessment for Statistics Education Report [6] stated that schools have responsibility to raise statistically literate individuals. Accordingly, the importance of statistical literacy is highlighted in numerous curriculum document, and concept related to statistics and probability are embedded in various curricula. 
Statistical literacy learning is applied at various levels, one of which is upper secondary school. Upper secondary students are required to have statistical literacy skills to be able to make decisions from various choices, for example choosing a university. The application of statistical learning in Indonesia has the appropriate benchmarks in the Permedikbud [7], the ability to relate to the basic competencies in the statistical material: a) analyzing the data, average value, median and mode, and spread of data to take a conclusion, make decisions, and make predictions, b) present and resolve issues related to data distribution, average value, median, mode, and data spread to take a conclusion, create a decisions, and make predictions. According to [8] to achieve statistical skills was needed by statistical knowledge. The knowledge consists of understanding, interpreting, and evaluating that can be called statistical literacy [9].

There are several factors that affect the difference in the statistical literacy capability of each student. These factors can be derived from the students (internal factor) or outside the students (external factor). Internal factors can be motivation, interest, talent, attitude, personality, way or learning style, etc. While external factors can be the influence of parents, curriculum, schools, and the environment. One of the internal factors, namely talent influenced by gender[10].

Gender is all traits inherent to men or women who are constructed based on biological factors, learning processes or a combination of both [11]. Based on research conducted [12] that gender differences in the orientation of student's achievement objectives, which are rendered in women (feminine) tend to demonstrate higher levels of language mastery and performance objectives than the one that is rendered men (masculine). According to[13] revealed that the level of language mastery of women are higher than men. Amir's research in[14] there is a difference between men and women on how to think. The female student has higher statistical literacy skill than the male student [15].

However, the gender has four types, that are masculine, feminine, androgynous, and indistinguishable[16]. This can be interpreted as female sex is not necessarily feminine, conversely male students are not necessarily masculine, there is a possibility that the person is of type androgyny or indistinguishable. Based on the background that has been displayed, researcher will conduct research under the heading "How is the Statistical Literacy of Upper Secondary Students Based On Gender Differences?". Based on the background that has been shown, the present study aims to describe statistical literacy of upper secondary students based on gender differences (Feminine, Masculine, androgynous, and indistinguishable)?

\section{Method}

\subsection{Sample of Research}

Prior to selecting student interviewed participating in the interview session, as many as 10 senior high schools with various background in terms of grade, gender and statistics ability in Nganjuk city participated a test consisting of Personal Attribute Questionnaire (PAQ). PAQ test adapted from Personal Attributes Questionnaire Spence, Helmreich \& Stapp 1973. The result of $P A Q$ is used to determine the sample which are masculine type, feminine type, androgynous type, or undistinguished type. Then, make groups from each type. From each type of sample will do the test of statistics ability. Then, as many as four samples is chosen with equal ability of statistics and different gender types. Four samples will do the test of statistics literacy. A test titled Statistical literacy (SLT) was adapted by using previous studies in the literature. More specifically, the Hafiyusholeh Statistics Test [4] to measure aspects of understanding data, interpreting data and communicating data. Test consisting nine items 
examining their statistics literacy around the concept of statistics.

\subsection{Instrument and Procedure}

Data were collected from the sample's work on written test which is different from the test given in the initial stage of selecting sample and follow up interviews. Based on the research of [2] stated that statistical literacy is the motivation and ability to access, understand, interpret, critically evaluate, and if relevant express opinions regarding statistical messages, data related argument, or issues involving uncertainty and risk.

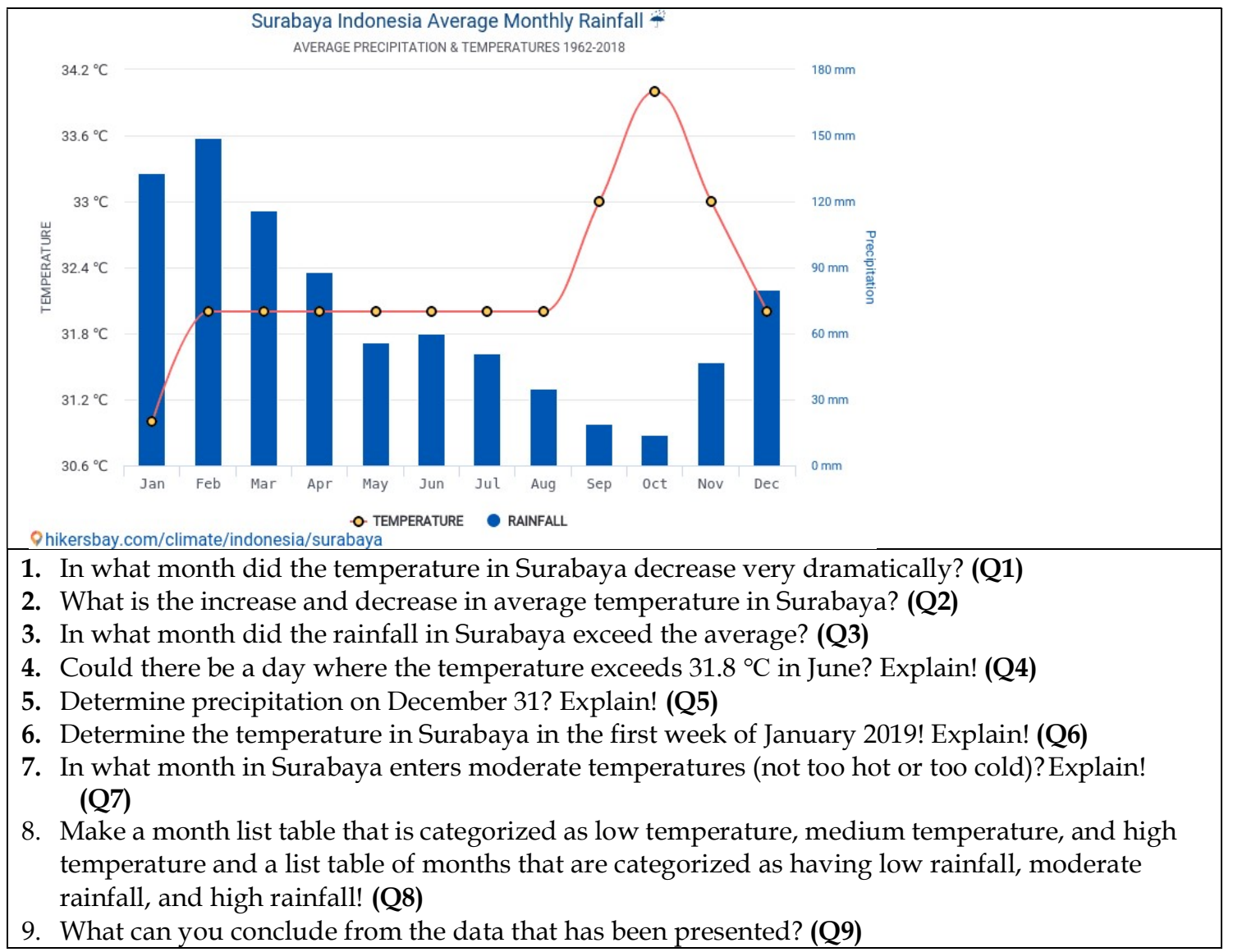

Figure 1. Statistical Literacy Test (SLT)

As can be observed in Figure 1, Q1, Q5 were the question that examined the first indicator that is understanding data. Specifically, these questions were related to the graphics, read information from what is written explicitly. While there were six questions related to the second indicator that is interpreting data, Q4 and Q6 make an prediction (make a decision) based on the data, Q2 and Q3 explain the data using concept of average, Q7 explain the data using concept of median, Q9 pay attention to general patterns and fluctuations in data to conclude the data. While there was one question relate to the third indicator that is communicating data in Q8, will be revealed the subject's ability to present data in the form of tables or graphs / diagrams. Related to aspects of statistical literacy, it can be seen in Table 1.

Those questions (Figure 1) in the instrument were compatible with relevant objective in the 
Indonesian curriculum. The instrument was validated by expert in terms of content, concept, and language as well as by learners, i.e. students' aside the sample to examine statistical literacy skills based on different gender. According to the feedback received from the students during the data collection tool was prepared. Subsequently, SLT was implemented to the participant in senior high school. The students were given 40 minutes to complete the test of nine questions measuring the ability to understand and, interpret data and communicate data. The indicators are explained in Table 1

Table 1. Indicator of Statistical Literacy Process

\begin{tabular}{|c|c|c|}
\hline $\begin{array}{l}\text { Statistical Literacy } \\
\text { Aspect }\end{array}$ & Indicator & Code \\
\hline Understanding data & $\begin{array}{l}\text { Read and explain data based on line diagrams by paying attention to the title } \\
\text { of the graph and the description of the existing axes. }\end{array}$ & Q1 \\
\hline Understanding data & $\begin{array}{l}\text { Read and determine the value in a bar chart by paying attention to points on } \\
\text { the axes. }\end{array}$ & Q5 \\
\hline Interpreting data & $\begin{array}{l}\text { Interpreting data using statistical average concepts with various data } \\
\text { fluctuations. }\end{array}$ & Q2 \\
\hline Interpreting data & $\begin{array}{l}\text { Interpreting data using the concept of averages accompanied by logical } \\
\text { reasoning. }\end{array}$ & Q3 \\
\hline Interpreting data & Evaluate critically by reasoning using statistical concepts. & Q4 \\
\hline Interpreting data & Make a prediction by taking into the given temperature. & Q5 \\
\hline Interpreting data & $\begin{array}{l}\text { Interpret their graph by taking into account the given temperature with } \\
\text { concept of median. }\end{array}$ & Q6 \\
\hline Interpreting data & Make conclusion from the data was given. & Q9 \\
\hline $\begin{array}{l}\text { Communicating } \\
\text { Data }\end{array}$ & Present and process statistical data in the form of tables or graphs / diagrams & Q9 \\
\hline
\end{tabular}

Table 2. Item Scoring Guidelines Test of Statistical Literacy for Student Answer and Argument

\begin{tabular}{lll}
\hline Responses Types for Student Answer and Argument & Classification of Responses & $\begin{array}{l}\text { Scor } \\
\text { e }\end{array}$ \\
\hline Incorrect or context-based responses & Non-Statistical/Incorrect & 0 \\
Correct, without appropriate statistical explanation & Pre-Statistical & 1 \\
Correct, with appropriate statistical explanations & Statistical & 2 \\
\hline
\end{tabular}

Based on Table 2 as a guide in making an assesment.. Those codes in the rubric are explained below in more detail.

Non-statistical/incorrect An incorrect responses includes both errors or mistakes and also inaccurate responses based on particular context that item has. For example from Q1, students answer January. Even though what was asked about was a drastic decrease, which means a decrease with the biggest difference from the previous month, which occurred in December. These are counted as context-based incorrect answer.

Pre-statistical This category includes a correct answer to the particular item though with an absence of appropriate statistical explanation. An example would be responses that recognize that there is an outlier in data set, though students cannot explain why this outlier should not be used in the concept of average, or that in this case the median should have been used instead of the average/mean.

Statistical A correct, statistical response is an indicator of statistical literacy. That students understand the statistical information and are able to critically evaluate it. In addition, they are able to provide statistical justification or explanations of their understanding, interpretation and communication. For example, responses that state whether or not the average temperature in a 
month is generalized to a particular day, giving statistical reasons such as in one month there are 30 days so there may be days where the temperature exceeds the average temperature in that month.

The researcher adopted the Coding scheme from students' answers and arguments from Yolcu [15]. Which means the scoring guidelines has been validated before. Explanation of the table 2 is used to determine the score obtained by the subject through SLT answers.

\subsection{Data Analysis}

Data of interview were analyzed by firstly reducing data, displaying data, and finally drawing conclusions and verification [17]. The conclusion was sought to description upper secondary students statistical literacy based on gender. To analyze data interview, we employ a modification of statistical literacy framework from Gal [2]. Data of subject's work analyzed using indicators that mentioned before. First, collecting data or grouping information provided by the subject. There was three kind of data. The first data is data to classify gender (determine subjects with masculine, feminine, androgynous or indistinguishable types). Then, the second data to analyze the ability of students' statistical literacy is based on each gender type. Then, the third data is interview data used to analyze students' answers in more depth. After the data is collected, reduce the data that is unnecessary or irrelevant. Second, do the presentation or presentation of data and data interpretation as the process of writing data in assessments that are converted to statistical literacy indicators (Table 1) and item scoring of student's work(in Table 2). Third, draw conclusions intended to describe the statistical literacy skills of upper secondary students. The process of drawing conclusions and verification is interpreted as the formulation of the results of research based on the results of the discussion of the data collected.

\section{Result and Discussion}

Data obtained from the results of PAQ test, SLT instruments, then analyzed using descriptive quantitative and qualitative. Students' answers were analyzed in accordance with the statistical indicators of literacy into material in describing the ability of statistical literacy in solving contextual problems based on gender.

Based on PAQ tests in categorizing gender with equal ability, the researchers chose 4 students, namely the initials ZSS with male gender as masculine gender subjects, ASA with female gender as feminine gender subjects, CA with female gender as androgynous gender subjects, and NMZ with female sex as a subject cannot be distinguished. Here the table that show student response and argument based on the three indicators. The statistical literacy test questions contain 9 items. Statistics literacy indicators in this study include (1) understanding data, items representing Q1 and Q5, (2) interpreting data, items representing Q2, Q3, Q4, Q6, Q7, and Q9, (3) communicating data, items that represent Q9.

Table 3. Scoring of Statistical Literacy Skill

\begin{tabular}{|c|c|c|c|c|}
\hline \multicolumn{4}{|c|}{ Statistical Literacy Skill } & \multirow{2}{*}{$\begin{array}{l}\text { Total } \\
\text { Score }\end{array}$} \\
\hline Types/Indicators & Understanding data & Interpreting data & Communicating data & \\
\hline
\end{tabular}




\begin{tabular}{|c|c|c|c|c|}
\hline \multirow{6}{*}{ Masculine (ZSS) } & Q1 (Non-Statistical), & Q2 (Statistical) & Q8 (Non-Statistical) & 6 \\
\hline & Q5 (Pre-Statistical) & Q3 (Non-Statistical) & & \\
\hline & & Q4 (Non-Statistical) & & \\
\hline & & Q6 (Statistical) & & \\
\hline & & Q7 (Pre-Statistical) & & \\
\hline & & Q9 (Statistical) & & \\
\hline \multirow{6}{*}{ Feminine (ASA) } & Q1 (Statistical) & Q2 (Statistical) & Q8 (Non-Statistical) & 14 \\
\hline & Q5 (Pre-Statistical) & Q3 (Statistical) & & \\
\hline & & Q4 (Statistical) & & \\
\hline & & Q6 (Statistical) & & \\
\hline & & Q7 (Pre-Statistical) & & \\
\hline & & Q9 (Statistical) & & \\
\hline \multirow[t]{6}{*}{ Androgynous (CA) } & Q1 (Statistical) & Q2 (Non-Statistical) & Q8 (Pre-Statistical) & 9 \\
\hline & Q5 (Pre-Statistical) & Q3 (Non-Statistical) & & \\
\hline & & Q4 (Non-Statistical) & & \\
\hline & & Q6 (Statistical) & & \\
\hline & & Q7 (Pre-Statistical) & & \\
\hline & & Q9 (Statistical) & & \\
\hline \multirow{6}{*}{$\begin{array}{l}\text { Cannot be } \\
\text { distinguished } \\
(\mathrm{NMZ})\end{array}$} & Q1 (Non-Statistical) & Q2 (Statistical) & Q8 (NA) & 6 \\
\hline & Q5 (NA) & Q3 (Pre-Statistical) & & \\
\hline & & Q4 (Statistical) & & \\
\hline & & Q6 (NA) & & \\
\hline & & Q7 (NA) & & \\
\hline & & Q9 (NA) & & \\
\hline
\end{tabular}

Based on Table 3, the total score of statistical literacy indicates that the literacy ability of the feminine type is higher than the other types with a total score of 14 . Then, followed by the androgynous types with total score of 9 . and the lowest in the type masculine and type cannot be distinguished by a total score of 6 . Next, students' statistical literacy will be explained as follows.

\subsection{The result of the ZSS settlement in Q1-Q9}

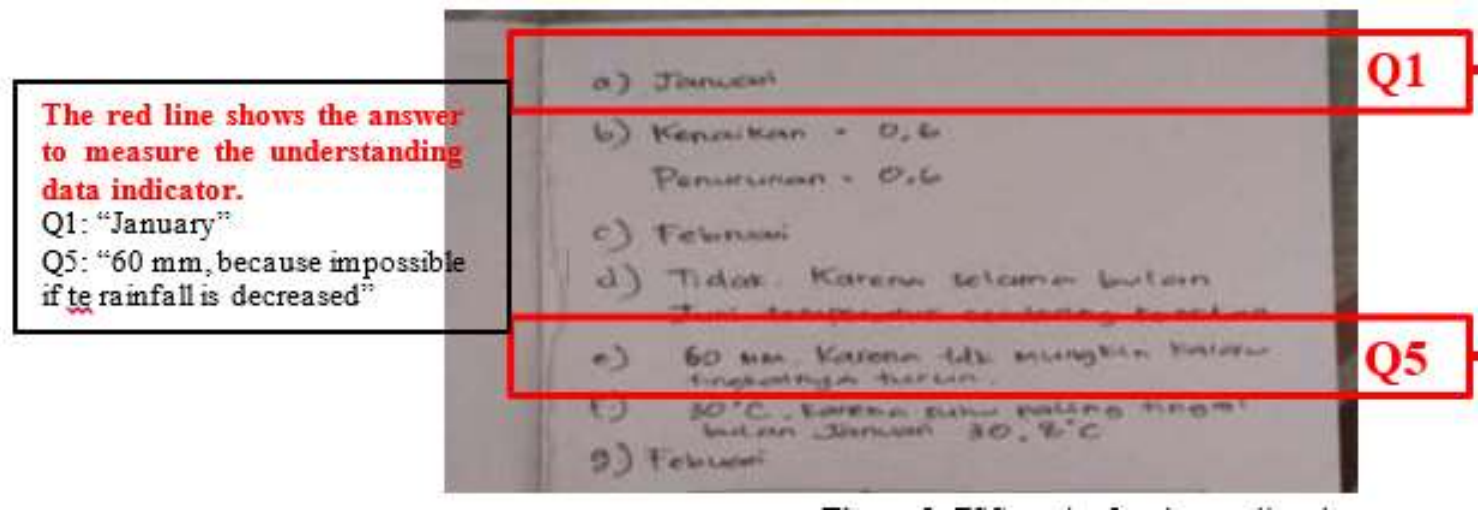

Figure 2. ZSS work of understanding data aspect.

In the process of understanding data in Q1 and Q5(in Figure 2). In the part (Q1), ZSS not careful enough in answering the question and understanding the graph. ZSS is only centered on the lowest graph even though in its question is a very drastic drop in temperature. In the part 
(Q5), ZSS use the strategy in read the data. ZSS was used strategies in reading data. ZSS pays attention to the title of the graph / diagram and the description of each axis provided, digging information directly from what is written explicitly on the graph. Based on the existing graph, interpret and explain the points in the graph as a relationship between the $\mathrm{x}$-axis and $\mathrm{y}$-axis. Then, ZSS answer Q5 with true answer. Therefore, ZSS is quite good at understanding data but lacks accuracy in answering one of the questions.

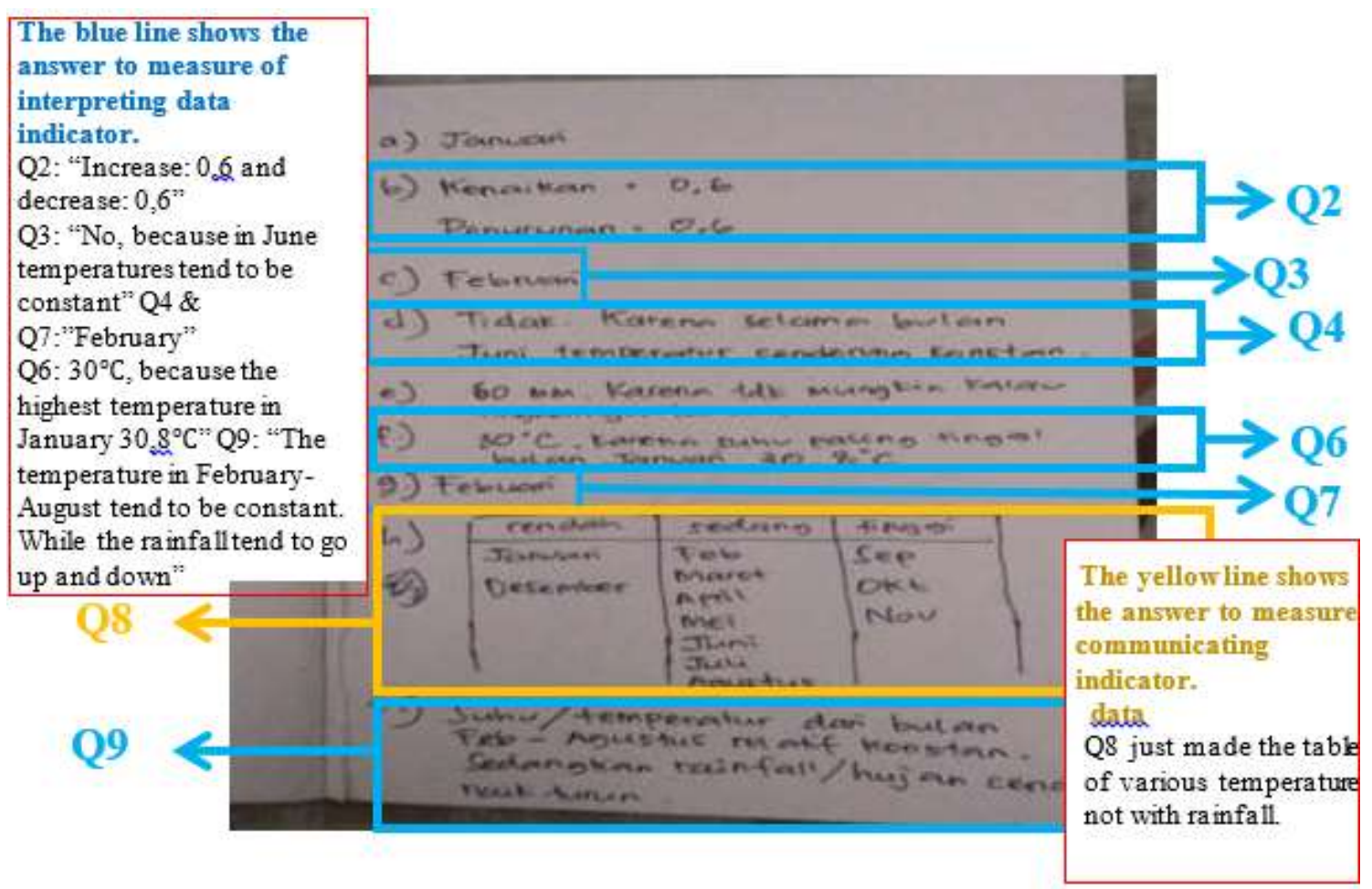

Figure 3. ZSS work of intrepreting data and communicating data aspect.

In the process of interpreting data in Q2,Q3,Q4,Q6,Q7, and Q9 (in Figure 3). In the part (Q2), ZSS identifies the graph in finding answer. ZSS can explain what information that he was got from the graph. ZSS considers the general pattern of fluctuations in determining the increase and decrease in data. ZSS records the number of temperature decreases from month to previous month and then determines the average by dividing the number of months that have decreased temperature. While the average temperature rise is obtained from noting the number of temperature increases from month to previous month, matching the number of months that experienced an increase in temperature. ZSS can use the concept of statistical averages well in the process of finding answers. In part (Q3), ZSS does not use the concept of statistical average to find answer. ZSS only uses estimates to answer questions, by determining the month with the highest rainfall so the answer becomes incomplete. In part (Q4), ZSS is not critical in answering questions. ZSS explained that all days of the month have the same temperature. In part (Q6), ZSS interpret data and use their arguments to explain the predictions that have been made. ZSS explains that with his arguments correctly and can be understood, ZSS can make 
predictions of the possibilities that will come correctly. In part (Q7), ZSS only answers one month with the forecast strategy in the existing graphs that temperatures are occurring in February. ZSS does not use the concept of median statistics correctly. So the answers become incomplete and inaccurate arguments. In part (Q9), ZSS reads and concludes the data on the graph correctly accompanied by clear arguments. But, not mention the relationship between temperature and rainfall. Overall, ZSS can interpret, can predict, and can deduce data correctly. However, in some cases, ZSS only uses estimates, not using statistical knowledge to find answers.

In process of communicating data in Q8 (in Figure 3), ZSS does not answer questions in full. ZSS only makes tables for temperatures that should be accompanied by rainfall. ZSS does not use statistical concepts in categorizing low, medium, high temperature types so the answers are wrong. ZSS can communicate data by making tables properly but there are errors in using statistical concepts.Therefore, based on item scoring student work in table 3 (understanding data, interpreting data, and communicating data) from ZSS gets a total score of 6 out of 18 (maximum score).

\subsection{The result of the ASA settlement in Q1-Q9}

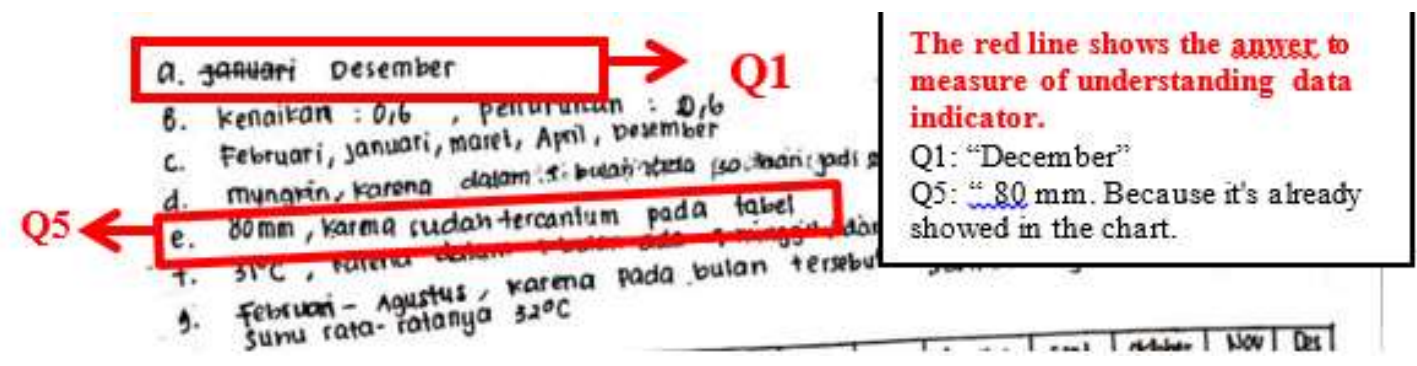

Figure 4. ASA work of Understanding Data Aspect

In process of understanding data on Q1 and Q5 ( Figure 4). In part Q1, ASA is very thorough in answering questions and reading graphs. ASA determines the temperature decrease from month to month until a temperature decrease is so drastic that the ASA answer is correct. In the part (Q5), ASA use the strategy in read the data. ASA uses strategies in reading data. ASA pays attention to the title of the graph/diagram and the description of each axis provided, digging information directly from what is written explicitly on the graph. Based on the existing graph, interpret and explain the points in the graph as a relationship between the $\mathrm{x}$-axis and $\mathrm{y}$-axis. Then, ASA answer Q5 with true answer. Therefore, ASA has the ability to understand data well and can careful in reading graph.

In process of interpreting data on Q2, Q3, Q4, Q6, Q7, and Q9 (In Figure 5). In part (Q2), ASA identifies the graph in finding answer. ASA can explain what information that she was got from the graph. ASA considers the general pattern of fluctuations in determining in increase and decrease in data. ASA records and calculate the number of temperature decrease from month to previous month and then determine the average by dividing the number of months 
that have decreased temperature. While the average temperature rise is obtained from nothing the number of temperature increases from month to previous month, matching the number of months that has an increase in temperature. ASA can use the concept of statistical average appropriately in the process of finding answer. In the part (Q3), ASA use the concept of statistical average to find answer. ASA determines the average rainfall in Surabaya for 12 months using the average concept. After obtaining an average value, ASA determines which month the rainfall is above average and get the right answer.

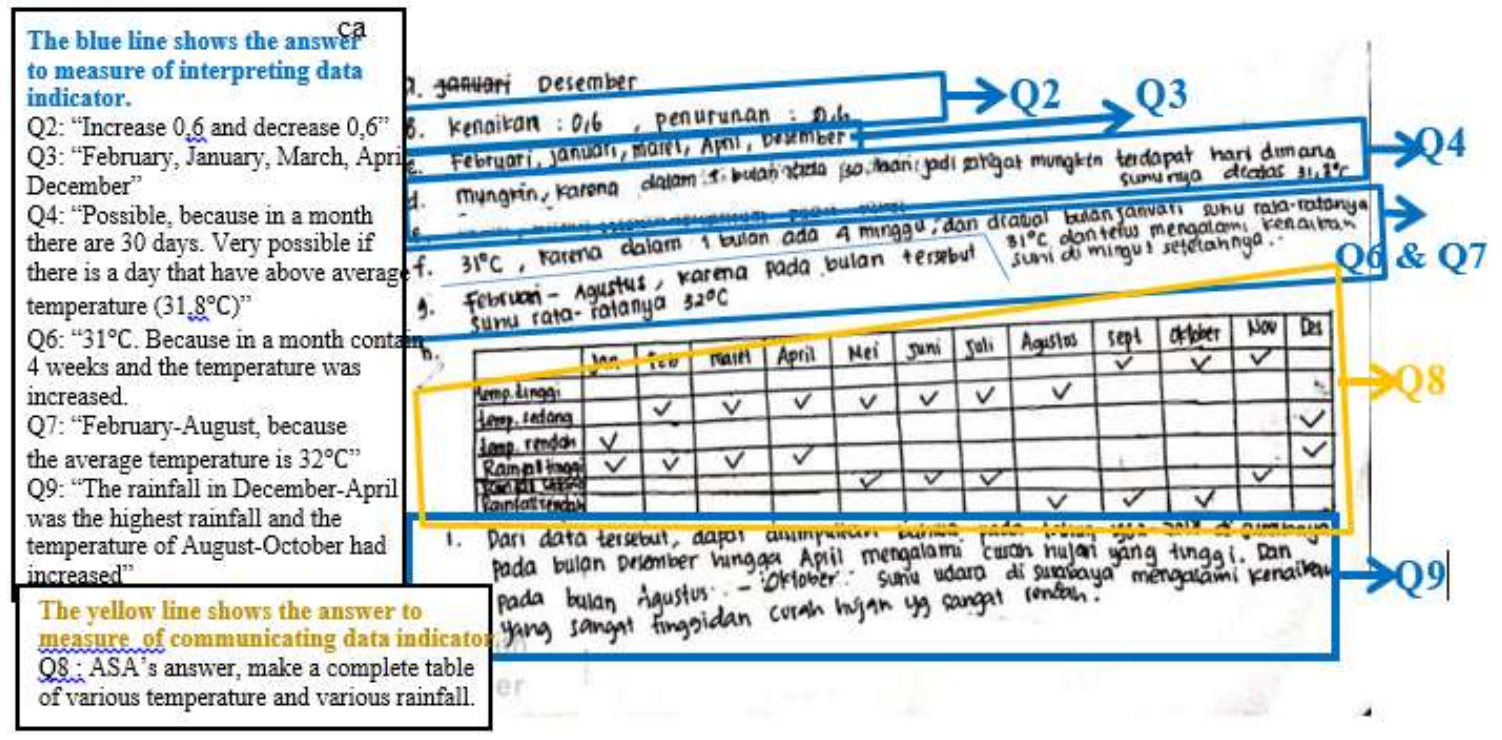

Figure 5. ASA work of interpreting data andcommunicating data aspect

In part (Q4), ASA is very critical in answering questions. ASA argues that in one month there are 30 days, and it is possible that the temperature per day is different and possible above average. In part (Q6), ASA interpret data and use their argument to explain the predictions that have been made. ASA explains that with her arguments correctly and can be understood, ASA can make predictions of the possibilities that will come correctly. In part (Q7), ASA can answer correctly. however, the arguments presented are incorrect. ASA uses the average concept to find answers when it should use the median concept. So the answers complete but the concept that has been used is incorrect. In part (Q9), ASA reads and concludes the data on graph correctly accompanied by clear arguments. But, not mention the relationship between temperature and rainfall. Overall, ASA can interpret, can predict, and can conclude data correctly. However, in some cases, ASA only uses estimates, not using statistical knowledge to find answers.

In process of communicating data on Q8( in Figure 5). In part (Q8), ASA creates a table by requiring a check mark. ASA answers complete tables for temperature and rainfall. However, ASA is not thorough in the last case so the answer is not perfectly correct. ASA does not use statistical concepts in creating tables. ASA only uses the estimation system to determine low, medium or high temperature months. Also in the determine of months with low, medium or high rainfall. . ASA can communicate data by making tables properly but there are errors in 
using statistical concepts.

Therefore, based on item scoring students work of SLT in table 3 (understanding data, interpreting data, and communicating data) from ASA gets a total score of 14 out of 18 (maximum score).

\subsection{The result of the CA settlement in Q1-Q9}

In process of understanding data on Q1 and Q5 ( Figure 6). In part (Q1), CA is very careful in answering questions and reading graphs. CA determines the temperature decrease from month to month until a temperature decrease is so drastic that the CA answer is correct. In part(Q5), In the part (Q5), CA use the strategy in read the data. CA uses strategies in reading data. CA pays attention to the title of the graph/diagram and the description of each axis provided, digging information directly from what is written explicitly on the graph. based on the existing graph, interpret and explain the points in the graph as a relationship between the $\mathrm{x}$ axis and y-axis. Then, CA answer Q5 with true answer. Therefore, CA has the ability to understand data well and can be careful in reading graph the question.

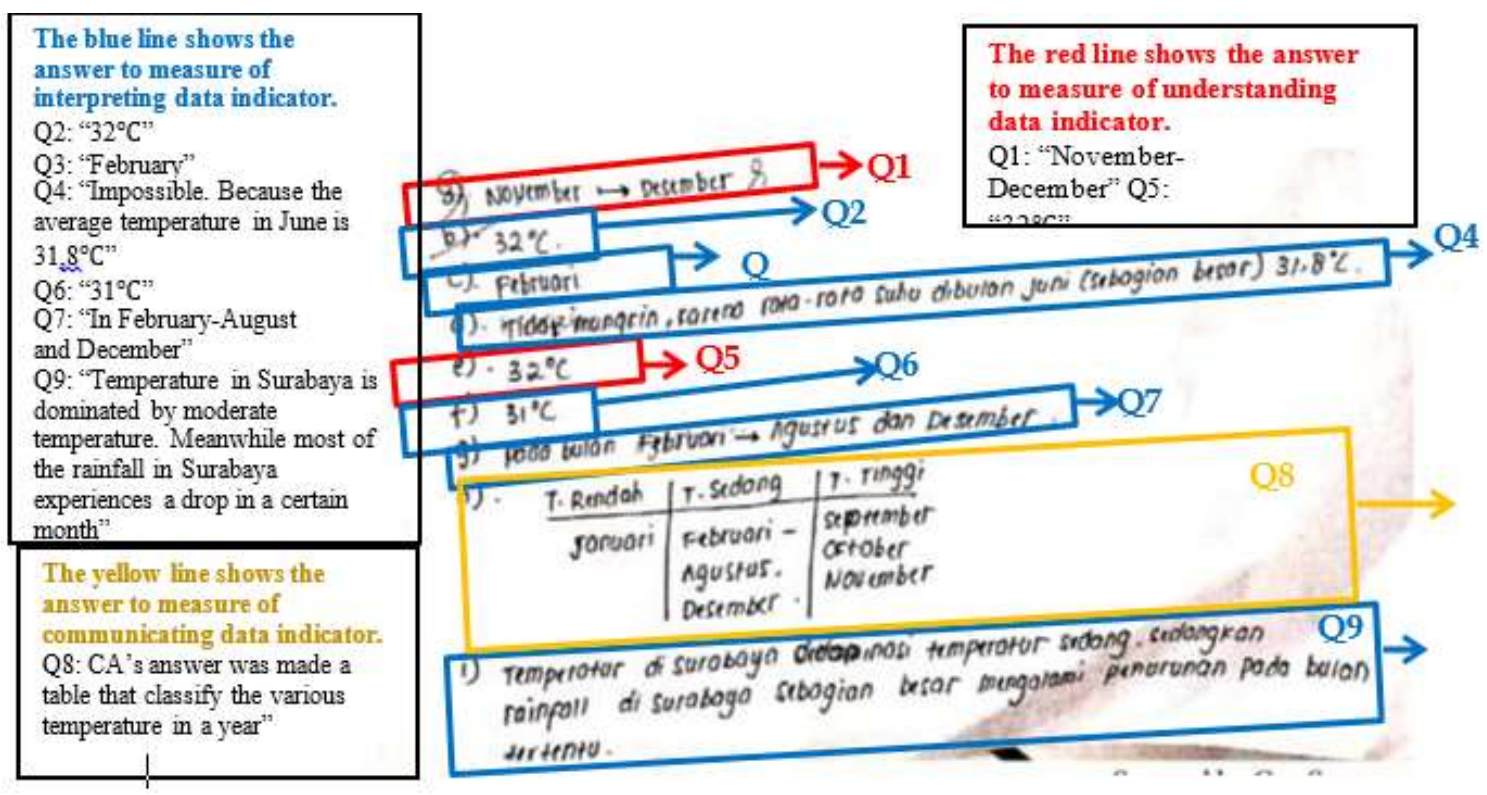

Figure 6. CA work of Understanding data, Interpreting data and Communicating data.

In process of interpreting data in Q2, Q3, Q4, Q6, Q7 and Q9(in Figure 6). In part (Q2), CA is not careful in answering questions. $\mathrm{CA}$ assumed that the question was the average temperature in Surabaya for 12 months so the answer is incorrect. CA generalizes the increase and decrease in temperature on average at one value. In the part (Q3), CA does not use the concept of statistical average to find answer. CA only uses estimates to answer questions, by determining the month with the highest rainfall so the answer becomes incomplete. In part (Q4), ZSS is not critical in answering questions.

ZSS explained that all days in June has same value as average that is $31,8^{\circ} \mathrm{C}$. In part (Q6), $\mathrm{CA}$ interpret data and use her arguments to explain the predictions that have been made. $\mathrm{CA}$ 
explains that with his arguments correctly and can be understood, CA can make predictions of the possibilities that will come correctly. In part (Q7), CA can answer correctly. However, the arguments presented are incorrect. CA uses estimates by interpreting the existing graph. So the answers complete but the concept that has been used is incorrect. In part (Q9), CA reads and concludes the data on graph correctly accompanied by clear arguments. But, not mention the relationship between temperature and rainfall. Overall, CA can interpret, can predict, and can conclude data correctly. However, in some cases, CA only uses estimates, not using statistical knowledge to find answers.

In the process of communicating data on Q9 (in Figure .6). In part (Q8), CA does not answer questions in full. CA only makes tables for temperatures that should be accompanied by rainfall. CA use statistical concepts in categorizing low, medium, high temperature types so the answers are true. Therefore, CA can communicate the data using the table correctly. Therefore, based on item scoring student work of SLT in table 3 (understanding data, interpreting data, and communicating data) from CA gets a total score of 9 out of 18 (maximum score).

\subsection{The result of the NMZ settlement in Q1-Q9}

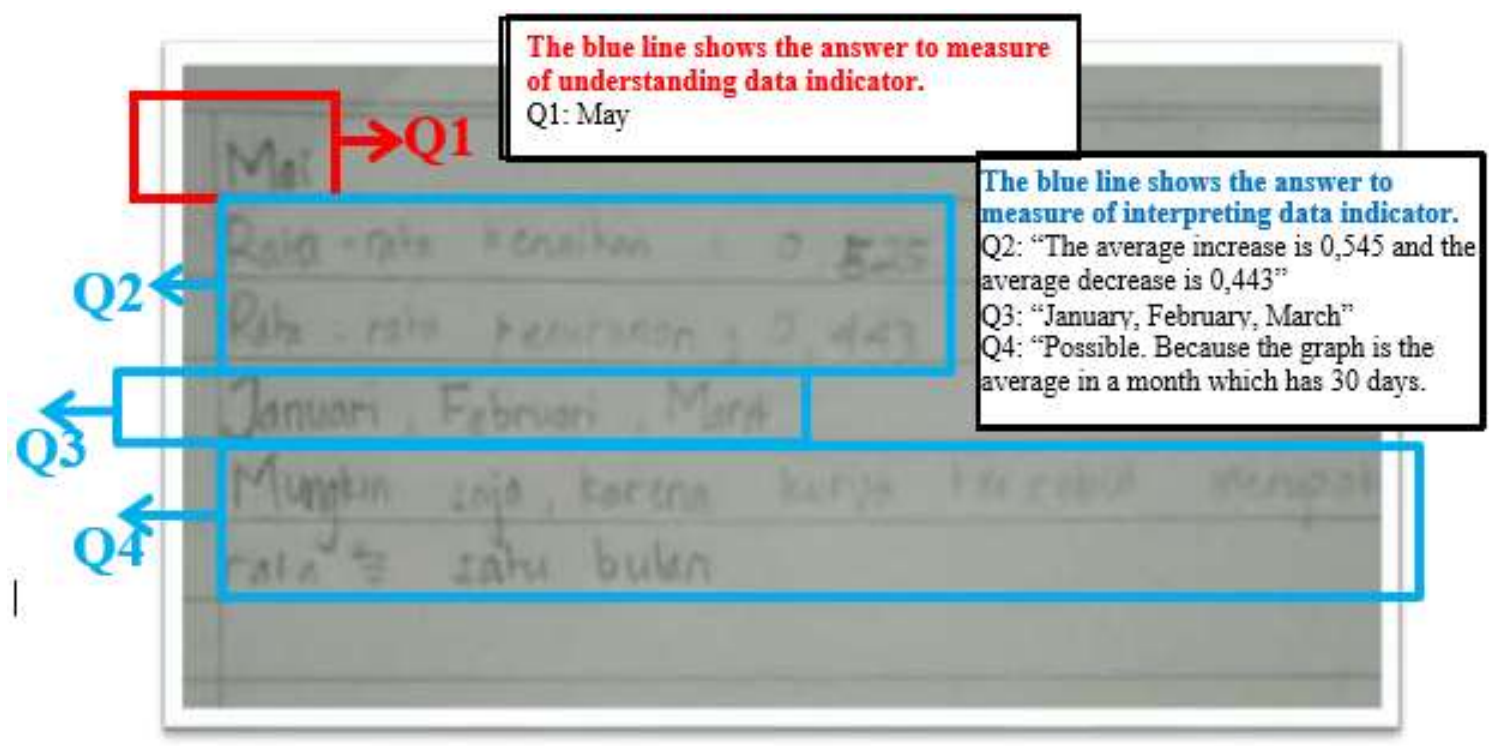

Figure 7. NMZ work of Understanding data and Intrepreting data aspect

In process of understanding data on Q1 and Q5 ( Figure 7). In part (Q1), NMZ was wrong in answering the question because NMZ was not careful in reading graphic symbols. NMZ thinks that bar charts for temperature and line charts for rainfall. In part (Q5), NMZ can't do it. therefore, NMZ cannot be analyzed more closely related to indicators understanding data.

In process of interpreting data on Q2, Q3, and Q4 ( Figure 7). In part (Q2), NMZ identifies the graph in finding answer. ASA can explain what information that she was got from the graph. NMZ considers the general pattern of fluctuations in determining in increase and decrease in data. NMZ records and calculate the number of temperature decrease from month to previous 
month and then determine the average by dividing the number of months that have decreased temperature. While the average temperature rise is obtained from nothing the number of temperature increases from month to previous month, matching the number of months that has an increase in temperature. NMZ can use the concept of statistical average appropriately in the process of finding answer. In the part (Q3), NMZ use the concept of statistical average to find answer. NMZ determines the average rainfall in Surabaya for 12 months using the average concept. After obtaining an average value, NMZ determines whichmonth the rainfall is above average and get the right answer. In part (Q4), NMZ is very critical in answering questions. $\mathrm{NMZ}$ argues that in one month there are 30 days, and it is possible that the temperature per day is different and possible above average. In part Q6, Q7, Q8. NMZ can't find the answer. Therefore, from her answer Q2, Q3, Q4 NMZ can use statistical concepts in interpreting, explaining data, and can also make predictions of the possibilities that will occur in the future.

In process of communicating data in Q8, NMZ can't find the answer. NMZ surrendered to find the answer so that it cannot be analyzed more closely in relation to indicators communicating data. Therefore, based on the item scoring student work in table 3 (understanding data, interpreting data, and communicating data) from NMZ gets a total score of 6 out of 18 (maximum score).

\section{Conclusion}

Based on Yolcu's research, there is no significant difference in statistical literacy abilities between the girls and the boys. It means the feminine sex and the masculine sex do not have statistical literacy abilities that are not much different[15]. But, in fact as female sex is not necessarily feminine, conversely male students are not necessarily masculine, there is a possibility that the person is of type androgyny or indistinguishable.

In this result of this study showed that upper secondary students statistical literacy performances, in which they were required to understand, interpret, and communicate data, could be interpret as high on feminine type, medium on androgynous type, and low on masculine type and cannot be distinguished type.

Based on the analysis of research results, statistical literacy of students based on gender differences has similarities and differences. In understanding data, students with masculine gender types are able to read statistical data with estimates without using the concept of statistics clearly. Meanwhile, students with feminine and androgynous gender types can read data and are supported with arguments that are easily understood. While students with gender types cannot be distinguished, cannot read graphs carefully so that errors occur in understanding the data.

In interpreting data, students with masculine gender types can explain the data but only use estimates not accompanied by statistical concepts, able to make predictions, unable to think critically related to data explanation and able to deduce data. While students with feminine gender types can explain the data clearly, are able to make predictions of future possibilities, can determine the value of increase and decrease in data, be able to think critically about the data presented and be able to make conclusions based on the data. While androgynous gender 
students cannot explain the data so answers do not match the question, can make predictions, are able to categorize data but do not use statistical concepts, cannot think critically about the data presented, and are able to make conclusions based on data. Whereas students with gender types cannot be distinguished, able to explain data accompanied by clear arguments based on statistical concepts, can think critically related to the data presented, and cannot be analysis related to the ability to deduce data.

In communicating data, students with masculine gender types and feminine gender types make mistakes in changing the shape of data from graphs to table forms. Students do not use statistical concepts in the process of making tables. While students with androgynous gender types can change the data from graph into table form correctly but are not accompanied by arguments related to the statistical concepts ussed but instead use the estimation strategy. While, students with gender types that cannot be distinguished cannot be analyzed further because the conditions of students who give up cannot work on the problems.

The reason for this result might be found in the distinction between the domains of mathematics and statistical literacy, the latter involves a greater linguistic aspect [2]. Watson [1] that may explain previously reported lack of gender differences in predicting interest in and self-efficacy for statistical literacy. Higher performances of female students in the area of statistical literacy can also be found in the literature. For example, Watson and Moritz [18] examined the possible gender on understanding the concept of sample. The results revealed that at lower grade levels, female students had higher level responses than male students, who gave more wrong responses on the basis of their contextual knowledge. This is in agreement with the findings of the current study. Therefore, the role of gender in statistical literacy in favor of girls is considered to be consistent with the statistics education literature, more recent research in mathematics education.

The result of this study contribute curriculum development in Indonesian upper secondary school curriculum, as objectives might be modified in relation to support for statistical literacy. For example objectives regarding interpretation of statistics claim might be added to the upper secondary school mathematics so the students would have an opportunity to make prediction and give possibility claim in a critical way. However, further research on statistical literacy is needed and qualitative research on how upper secondary students critically interpret statistical claims would be important contribution to the statistics education literature.

The lack of grade level difference in statistical literacy scores of upper secondary students in this study did not indicate there was no developmental sequence. The students in this study were from adjacent grades and of similar ages. More research should be carried out using a wider range of grade levels to document whether or not there is a developmental hierarchy in statistical literacy scores.

The results of this study in terms of gender indicated that more research is needed to understand why and how this gap occurs in favor of female students. However, in classroom settings while teaching statistical concepts, a diverse range of contexts and examples should be considered in order to engage masculine, feminine, androgynous, and cannot be distinguished students types with the statistical content.

In this study, which aimed at investigating role of gender on statistical literacy of upper 
secondary schools, there were several extraneous variable such as students' background and previous mathematical knowledge which were not controlled for. Furthermore, the study was conducted in Nganjuk city and therefore, the finding of this study might be limited in its application to a more general population of upper secondary students. Yet, the result can be generalized to students whose context and curriculum is similar to this study. Another limitation was that the results of the present study were based on quantitative data collected from through the SLT.

\section{References}

[1] J. M. Watson, "Statistical Literacy at School: Growth and Goals." Lawrence Erlbaum, NJ Mahwah, 2006.

[2] I. Gal, “Adults' Statistical Literacy: Meanings, Components, Responsibilities,” Int. Stat. Rev., vol. 70, no. 1, pp. 1-25, 2002, doi: 10.1111/j.1751-5823.2002.tb00336.x.

[3] D. J. Rumsey, "Statistical literacy as a goal for introductory statistics courses," J. Stat. Educ., vol. 10, no. 3, 2002, doi: 10.1080/10691898.2002.11910678.

[4] M. Hafiyusholeh, K. Budayasa, and T. Y. E. Siswono, "Literasi Statistik: Siswa SMA dalam Membaca, Menafsirkan, dan Menyimpulkan Data," Pros. SI MaNIs (Seminar Nas. Integr. Mat. dan Nilai Islam., vol. 1, no. 1, pp. 79-85, 2017.

[5] J. M. Watson, "Statistical Literacy in the Elementary School: Opportunities for Problem Posing," Math. Probl. posing From Res. to Eff. Pract., pp. 241-256, 2015.

[6] G. . C Franklin, "Guidelines forassessment and instruction in statistics education (GAISE) report: A pre-K-12 curriculum framework.," VA Alexandria, 2005.

[7] Permendikbud, Permendikbud Nomor 24 Tentang Kompetensi Inti dan Kompetensi Dasar Tahun 2016. Jakarta: Kemendikbud, 2016.

[8] C. S. Carmichael, M. Phil, M. Ed, and B. Sc, "The development of middle school children 's interest in statistical literacy," no. November, 2010.

[9] J. Watson, “Assessing Statistical Thinking Using the Media,” 2016.

[10] M. Fakih, Analisis Gender dan Transformasi sosial. Yogyakarta: INSISTPress, 2008.

[11] I. Risywandha and S. Khabibah, "Literasi Matematika Siswa Sma Kelas X Dalam Menyelesaikan Soal Model Pisa Ditinjau Dari Perbedaan Gender," MATHEdunesa, vol. 7, no. 2, pp. 248-255, 2018. 
How is the statistical literacy of Upper Secondary Students Based On Gender Differences?

[12] A. M. Hyde, J.S. and Durik, "Gender, competence, and motivation.," Handb. competence Motiv., p. pp.375-391, 2005.

[13] M. L. Kristyasari, S. Yamtinah, S. B. Utomo, Ashadi, and N. Y. Indriyanti, "Gender Differences in Students' Science Literacy towards Learning on Integrated Science Subject," J. Phys. Conf. Ser., vol. 1097, no. 1, 2018, doi: 10.1088/1742-6596/1097/1/012002.

[14] F. F. W. Putri and M. P. Dr. Masiyah, "Profil Kemampuan Penalaran Siswa Smp Dalam Menyelesaikan Masalah Matematika Ditinjau Dari Tipe Kepribadian Dan Jenis Kelamin," J. Ilm. Pendidik. Mat. mathedunesa, vol. 8, no. 58, pp. 38-45, 2019.

[15] A. Yolcu, "Middle school students' statistical literacy: Role of grade level and gender," Stat. Educ. Res. J., vol. 13, no. 2, pp. 118-131, 2014.

[16] Bem, Pengantar Psikologi Edisi 1 dan 2, Edisi 1 da. Jakarta: Penerbit Airlangga, 1997.

[17] Miles \& Hubberman, Qualitative data analysis: an expanded sourcebook (2nd. Ed). London: Sage.

[18] J. Watson, J., \& Moritz, "Development of understanding of sampling for statistical literacy.," J. Math. Behav., vol. 19(1), pp. 109-136, 2000. 